Vietnam Journal of Mechanics, VAST, Vol.33, No. 1 (2011), pp. $13-26$

\title{
A 6DOF SUPER ELEMENT FOR NONLINEAR ANALYSIS OF COMPOSITE FRAMES WITH PARTIAL INTERACTION AND SEMI-RIGID CONNECTIONS
}

\author{
Le Luong Bao Nghi, Bui Cong Thanh \\ University of Technology, VNU-HCMC
}

\begin{abstract}
This paper presents a displacement - based finite element formulation for nonlinear analysis of steel - concrete composite planar frames subjected to combined action of gravity and lateral loads. A 6DOF super element is proposed for modelling composite beam, allowing for partial interaction between the steel beam and the concrete slab, semi - rigid nature of beam to column composite connection and material nonlinearity. The load control method and the displacement control method are utilized for tracing the structural equilibrium paths, and the direct method is utilized for solving the nonlinear problem. Numerical examples, concerning a two-span continuous composite beam, a portal composite frame and a six - storey composite frame, are performed. The results are compared with experience data or theoretical results from other studies and are discussed for influences of the factors mentioned above on behaviour of composite beams and composite frames.
\end{abstract}

Key words: Super finite element, composite constructions, partial interaction, semi rigid composite connections, nonlinear analysis.

\section{INTRODUCTION}

Steel - concrete composite constructions have been widely used in buildings as well as bridges thanks to their ability to combine the advantages of both steel and concrete. Therefore, the research into this type of construction to find out an efficient, robust and accurate method for analysis of this type has always been necessary. The relative longitudinal slip between the concrete slab and steel joist due to the deformability of the shear connectors is referred to as the partial interaction (PI) in composite beams. This nature has a significant influence on the behaviour of the composite beams and the composite frames as well. Another nature of composite frame that affects highly the behaviours of composite beams and frames is semi - rigid composite connections. It is very important to account for the different behaviours of the composite connection under sagging moment and hogging moment due to different contributions of the concrete and rebar to the bare steel connection. In order to capture more precision in analysis of the composite frames, especially in the limit states, it is very essential to account for nonlinear behaviour of steel, concrete, shear connectors and semi - rigid connections. Two methods, which are usually used for considering the material nonlinearity of member, are the lumped and distributed 
models. The lumped models, which concentrate all material nonlinearity at the member ends, seem to be appropriate for steel frame analysis. The distributed models, on the other hand, are more accurate and rational due to monitoring entirely the material nonlinearity along the member length by means of numerical integration. Thus, the distributed models are efficient for modelling members made up of two different kinds of materials and for members with cracked sections like composite members.

In this paper, the $8 \mathrm{DOF}$ displacement-based element proposed by Dall'Asta and Zona $[1,2]$ is employed to modelling segments of planar composite beam allowing for PI. The nonlinear behaviour of materials of this element derives entirely from the constitutive laws by means of numerical integration. To improve the accuracy for the nonlinear analysis, a number of the sequential 8DOF elements are combined to form the $8 \mathrm{DOF}$ super element for modelling entirely one composite beam. To consider the semi-rigid nature of the composite connection, firstly, two rotational springs are attached to the 8DOF super element's ends for modelling the bare steel connections. Then, additional rotational stiffness due to the contribution of concrete and rebars is provided by the slab-to-column link. With that description, the $8 \mathrm{DOF}$ super element is modified to formulate firstly a new $8 \mathrm{DOF}$ element because of the attaching the springs, and then a $6 \mathrm{DOF}$ element by constrained conditions obtained from slab-to-column links. Therefore, the 6DOF super element for modelling the composite beam allowing for PI, material nonlinearity and semi-rigid composite connections is obtained. The direct method is utilized for solving nonlinear equilibrium equation, and the load control method and the displacement control method are utilized for tracing the structural equilibrium part.

\section{FINITE ELEMENT FORMULATIONS}

\subsection{DOF element for modelling composite beam with PI}

The 8 DOF displacement based element [1, 2] (Fig. 1) is utilized for modelling a segment of planar steel-concrete composite beam with partial interaction. The formulation of this element is based on the Newmark kinematical model, where the Euler-Bernoulli beam theory is used to model the two parts of the composite beam; the effects of the deformable shear connection are accounted for by using an interface model with distributed bond, preserving the contact between the components while allowing for the longitudinal slip.

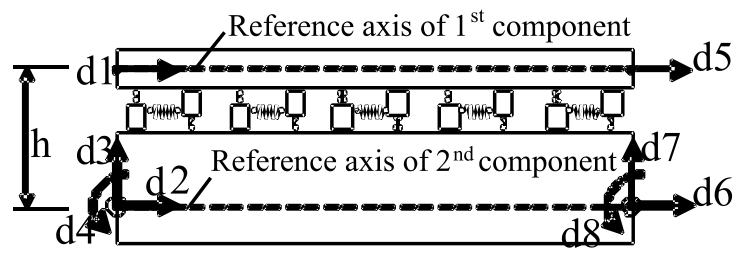

Fig. 1. 8DOF finite element 
The displacement formulation of the finite element method introduces a polynomial approximation of the displacement field of the element:

$$
\tilde{\mathbf{u}}=\mathbf{N d}
$$

( $\tilde{\bullet}$ denotes the approximation of field ) where $\mathbf{u}$ is generalized vector representing the displacement field:

$$
\mathbf{u}^{T}=\left[\begin{array}{lll}
w_{1} & w_{2} & v
\end{array}\right]
$$

(with $v$ is the deflection of the beam and $w_{\alpha}$ is the axial displacement of $\alpha$-th component $(\alpha=1,2)$ at its reference axis), $\mathbf{d}$ is the vector of the nodal displacements (Fig. 1) and $\mathbf{N}$ is the matrix of shape functions. In this element, the deflection is described by the cubic Hermite polynomial and the axial displacements of the two components are described by linear functions.

Using the principal of virtual work, the equilibrium equation is written in the following form:

$$
\mathbf{K}_{e} \mathbf{d}=\mathbf{P}_{e}
$$

where

$$
\mathbf{K}_{e}=\int_{0}^{L e} \mathbf{B}^{T} \mathbf{D B} d z \text { and } \mathbf{P}_{e}=\int_{0}^{L e}(\mathrm{H} \mathrm{N})^{T} \mathbf{p} d z
$$

are the stiffness matrix and nodal force vector of the element. In above equations, $\mathbf{B}$ is strain-displacement matrix defined from the following equation:

$$
\tilde{\varepsilon}_{\mathbf{u}}=D \tilde{\mathbf{u}}=D \mathbf{N d}=\mathbf{B d}
$$

where $D$ is the differential operator representing compatibility conditions:

$$
\varepsilon=\left[\begin{array}{l}
\varepsilon_{1} \\
\varepsilon_{2} \\
\chi \\
s
\end{array}\right]=\left[\begin{array}{lll}
\partial & 0 & 0 \\
0 & \partial & 0 \\
0 & 0 & -\partial^{2} \\
1 & -1 & h \partial
\end{array}\right]\left[\begin{array}{l}
w_{1} \\
w_{2} \\
v
\end{array}\right]=D \mathbf{u}
$$

(with $\varepsilon_{\alpha}=w_{\alpha}^{\prime}$ is the axial strain of $\alpha-t h$ component $(\alpha=1,2)$ at its reference axis, $\chi=-v^{\prime \prime}$ is the curvature, $s$ is the slip and $h$ is the distance of reference axes of the two components). $\mathbf{D}$ is the matrix of constitutive relation between generalized stress $\boldsymbol{r}$ and strain $\varepsilon(\mathbf{r}=\mathbf{D} \varepsilon)$

$$
\mathbf{D}=\left[\begin{array}{llll}
\overline{E A}_{1} & 0 & \overline{E S}_{1} & 0 \\
0 & \overline{E A}_{2} & \overline{E S}_{2} & 0 \\
\overline{E S}_{1} & \overline{E S}_{2} & \overline{E J}_{12} & 0 \\
0 & 0 & 0 & k
\end{array}\right]
$$

where

$$
\mathbf{r}^{T}=\left[\begin{array}{llll}
N_{1} & N_{2} & M_{12} & q
\end{array}\right]
$$

and

$$
\begin{aligned}
& {\overline{E A_{\alpha}}}=\int_{A_{\alpha}} E_{\alpha} d A_{\alpha}=\int_{A_{\alpha}} \frac{d \sigma_{z \alpha}}{d \varepsilon_{z \alpha}} d A_{\alpha}, \\
& \overline{E S}_{\alpha}=\int_{A_{\alpha}} E_{\alpha}\left(y-y_{\alpha}\right) d A_{\alpha}=\int_{A_{\alpha}} \frac{d \sigma_{z \alpha}}{d \varepsilon_{z \alpha}}\left(y-y_{\alpha}\right) d A_{\alpha}, \\
& \overline{E J}_{\alpha}=\int_{A_{\alpha}} E_{\alpha}\left(y-y_{\alpha}\right)^{2} d A_{\alpha}=\int_{A_{\alpha}} \frac{d \sigma_{z \alpha}}{d \varepsilon_{z \alpha}}\left(y-y_{\alpha}\right)^{2} d A_{\alpha}
\end{aligned}
$$


(with $\overline{E J}_{12}=\overline{E J}_{1}+\overline{E J}_{2}, k$ is the connection stiffness, $N_{\alpha}$ is the axial forces on $\alpha-t h$ component $(\alpha=1,2), M_{12}$ is the summation of the bending moments $M_{\alpha}$ on $\alpha-t h$ component and $q$ the interface shear force). $H$ is the differential operator:

$$
H=\left[\begin{array}{lll}
1 & 0 & 0 \\
0 & 1 & 0 \\
0 & 0 & 1 \\
0 & 0 & \partial
\end{array}\right]
$$

and $\mathbf{p}$ is the external forces written in generalized vectors as follows:

$$
\mathbf{p}^{T}=\left[\begin{array}{llll}
p_{z 1} & p_{z 2} & p_{y} & m_{x}
\end{array}\right]
$$

where $p_{z 1}, p_{z 2}, p_{y}, m_{x}$ are two distributed loads, transverse distributed load and distributed couple, respectively.

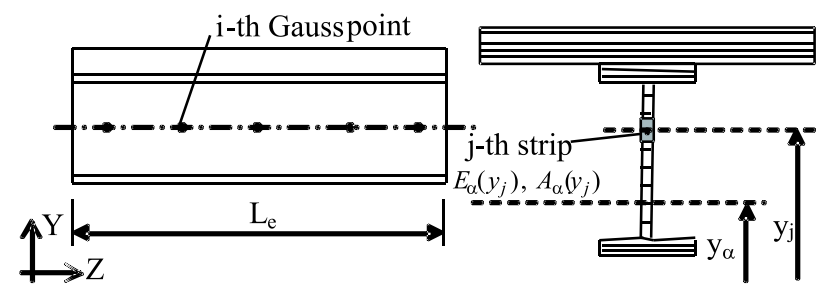

Fig. 2. Numerical integration for calculating stiffness matrix

To account the material nonlinearity of the element, the stiffness matrix and load vector are formulated by means of numerical integration, using the trapezoidal rule through the thickness (the cross-section is subdivided in rectangle strips parallel to the $\mathrm{x}$-axis) and the Gauss-Lobatto rule along the element length as shown in Fig. 2.

\subsection{Super element for modelling composite beam with PI and semi-rigid connections}

Due to using the low order shape functions for the 8DOF element, it is necessary to use a number of the $8 \mathrm{DOF}$ elements for modelling one composite beam in order to describe the displacement field better as well as increase the accuracy in nonlinear analysis. That means the composite beam is subdivided along its length into a number of segments, each of which is modelled by one $8 \mathrm{DOF}$ element (Fig. 3a). However, this subdivision brings about the difficulties in numerical computation due to the large size of the global stiffness matrix, and in managing the input and output data. To overcome these problems, these discrete $8 \mathrm{DOF}$ elements are combined to form one element referred to as 8DOF super element (Fig. 3b) for entirely modelling the composite beam. The stiffness equation for the discrete $8 \mathrm{DOF}$ elements is given by:

$$
\mathbf{K} \cdot \mathbf{d}=\left[\begin{array}{ll}
\mathbf{K}_{11} & \mathrm{~K}_{12} \\
\mathbf{K}_{21} & \mathbf{K}_{22}
\end{array}\right]\left\{\begin{array}{l}
\mathbf{d}_{1} \\
\mathbf{d}_{2}
\end{array}\right\}=\left\{\begin{array}{l}
\mathbf{P}_{1} \\
\mathbf{P}_{2}
\end{array}\right\}
$$

where $\mathbf{K}$ is the overall stiffness matrix obtained by assembling the stiffness matrices of internal elements, $\mathbf{d}_{\mathbf{1}}$ and $\mathbf{P}_{1}$ are the displacement and force nodal vectors of the nodes 
at member's ends, $\mathbf{d}_{2}$ and $\mathbf{P}_{2}$ are the displacement and force nodal vectors of the internal nodes. Through static condensation, the stiffness matrix and the force nodal vector (not including reaction force vector) of the super element are defined:

$$
\mathbf{K}_{\mathrm{e}(8 \times 8)}=\mathbf{K}_{11}-\mathbf{K}_{12} \mathbf{K}_{22}^{-1} \mathbf{K}_{21} \text { and } \mathbf{P}^{\prime}(8 \times 1)=\mathbf{P}^{\prime}{ }_{1}-\mathbf{K}_{12} \mathbf{K}_{22}^{-1} \mathbf{P}_{2}
$$

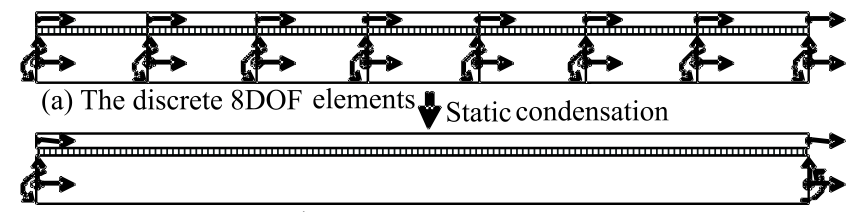

(b) The 8DOF super element

Fig. 3. The $8 \mathrm{DOF}$ super element for composite beam

In this study, a model of composite joint is proposed as shown in Fig. 4. In this model, the bare steel connection is modelled by a rotational spring characterized by momentrotation curve, and the contribution of the reinforced concrete slab to rotational stiffness is considered by a slab-to-column link. This link is the assumption that the node associated with the reinforced concrete slab is connected to the point, at which the reference axes of the column and of the slab intersect as shown in Fig.4. This model makes it possible to consider the different behaviours of the composite joint under sagging and hogging moments due to different behaviours of concrete in compression and tension.

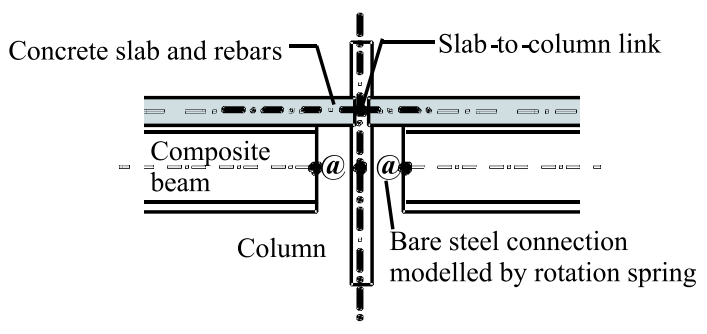

Fig. 4. Model of semi-rigid composite joint

To account the semi-rigid nature of composite joint in composite beam, firstly, two rotation springs are attached at the ends of the $8 \mathrm{DOF}$ super element for modelling the bare steel connection (Fig. 5a). The stiffness equation for the composite beam element and the two springs shown as three separate elements in Fig.5a are given by:

$$
\begin{aligned}
& \left.\begin{array}{lllll}
\mathbf{K}_{\mathbf{e}(\mathbf{8} \times \mathbf{8})} & & & \\
& R_{1} & -R_{1} & & \\
& -R_{1} & R_{1} & & \\
& & & R_{2} & -R_{2} \\
& & -R_{2} & R_{2}
\end{array}\right]\left\{\begin{array}{l}
\mathbf{d}_{(\mathbf{8} \times \mathbf{1})} \\
d_{9} \\
d_{10} \\
d_{11} \\
d_{12}
\end{array}\right\}=\left\{\begin{array}{l}
\mathbf{P}_{\mathbf{e}(\mathbf{8} \times \mathbf{1})} \\
P_{9} \\
P_{10} \\
P_{11} \\
P_{12}
\end{array}\right\} \\
& \text { or } \mathbf{K}_{(\mathbf{1 2 \times 1 2})} \cdot \mathbf{d}_{(\mathbf{1 2 \times 1})}=\mathbf{P}_{(\mathbf{1 2 \times 1})}
\end{aligned}
$$


where $R_{1}$ and $R_{2}$ are the stiffness of the two springs. Then the three elements are connected together to form one element having 10 degrees of freedom (DOFs) as shown in Fig. 5b. The relationship between the 12 DOFs of the element in Fig. 5a and the 10 DOFs of the element in Fig.5b is defined by the transformation matrix:

$$
\mathbf{T}_{(12 \times 10)}=\left[\begin{array}{cccccccccc}
1 & 0 & 0 & 0 & 0 & 0 & 0 & 0 & 0 & 0 \\
0 & 1 & 0 & 0 & 0 & 0 & 0 & 0 & 0 & 0 \\
0 & 0 & 1 & 0 & 0 & 0 & 0 & 0 & 0 & 0 \\
0 & 0 & 0 & 0 & 0 & 0 & 0 & 0 & 1 & 0 \\
0 & 0 & 0 & 0 & 1 & 0 & 0 & 0 & 0 & 0 \\
0 & 0 & 0 & 0 & 0 & 1 & 0 & 0 & 0 & 0 \\
0 & 0 & 0 & 0 & 0 & 0 & 1 & 0 & 0 & 0 \\
0 & 0 & 0 & 0 & 0 & 0 & 0 & 0 & 0 & 1 \\
0 & 0 & 0 & 0 & 0 & 0 & 0 & 0 & 1 & 0 \\
0 & 0 & 0 & 1 & 0 & 0 & 0 & 0 & 0 & 0 \\
0 & 0 & 0 & 0 & 0 & 0 & 0 & 0 & 0 & 1 \\
0 & 0 & 0 & 0 & 0 & 0 & 0 & 1 & 0 & 0
\end{array}\right]
$$

Therefore, from Eqs. (14) and (15), the stiffness matrix and the force nodal vector of the element in Fig. 5b is given by:

$$
\mathbf{K}_{(10 \times 10)}=\left(\mathbf{T}_{(12 \times 10)}\right)^{T} \cdot \mathbf{K}_{(\mathbf{1 2 \times 1 2})} \cdot \mathbf{T}_{(12 \times 10)} \text { and } \mathbf{P}_{(10 \times 1)}=\left(\mathbf{T}_{(12 \times 10)}\right)^{T} \cdot \mathbf{P}_{(12 \times 1)}
$$

To obtain the 8DOF element as shown in Fig. 5c, static condensation is employed to eliminate the DOFs 9' and 10'of the element in Fig. 5b. Thus, the stiffness equation for the element in Fig.5b is expressed as:

$$
\left[\begin{array}{ll}
\mathbf{K}_{(8 \times 8)} & \mathbf{K}_{(8 \times 2)} \\
\mathbf{K}_{(2 \times 8)} & \mathbf{K}_{(2 \times 2)}
\end{array}\right]\left\{\begin{array}{l}
\mathbf{d}_{(8 \times 1)} \\
\mathbf{d}_{(2 \times 1)}
\end{array}\right\}=\left\{\begin{array}{l}
\mathbf{P}_{(8 \times 1)} \\
\mathbf{P}_{(2 \times 1)}
\end{array}\right\}
$$

where $\mathbf{d}_{(8 \times 1)}$ and $\mathbf{P}_{(8 \times 1)}$ are the displacement and forces corresponding to the exterior

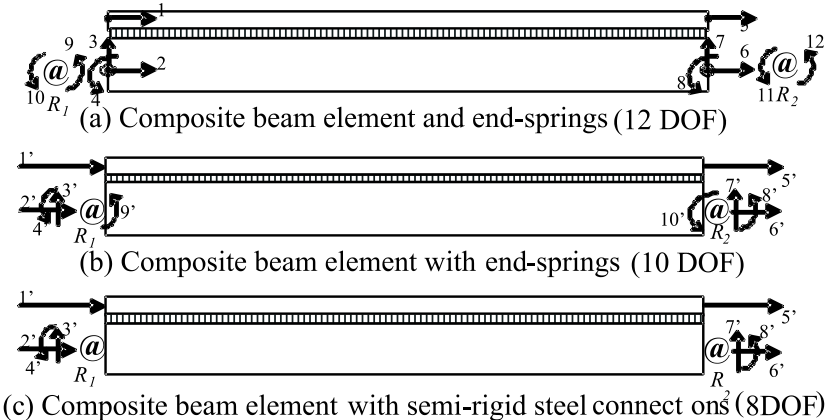

Fig. 5. The 8DOF super element for composite beam with semi-rigid connections

DOFs 1' to 6', and $\mathbf{d}_{(2 \times 1)}$ and $\mathbf{P}_{(2 \times 1)}$ are the displacements and forces corresponding to the interior DOFs 7' to 8'. Therefore, from Eqs. (17), the stiffness matrix and the force nodal 
vector of the $8 \mathrm{DOF}$ element in Fig. $5 \mathrm{c}$ is given by:

$$
\mathbf{K}_{e(8 \times 8)}^{S R}=\mathbf{K}_{(8 \times 8)}-\mathbf{K}_{(8 \times 2)} \cdot \mathbf{K}_{(2 \times 2)}^{-1} \cdot \mathbf{K}_{(2 \times 8)} \text { and } \mathbf{P}_{e(8 \times 1)}^{S R}=\mathbf{P}_{(8 \times 8)}^{\prime}-\mathbf{K}_{(8 \times 2)} \mathbf{K}_{(\mathbf{2} \times \mathbf{2})}^{-\mathbf{1}} \mathbf{P}_{(2 \times 8)}
$$

(b) Composite beam element in planar frame (6 DOF)

Fig. 6. The 6DOF super element for composite beam with semi-rigid connections

To consider the contribution of the reinforced concrete component to the composite joint, the slab-to-column links proposed above are employed. On the column's reference axes, if the differences in deflection due to bending moment within the distances $h$ (Fig. 6a) are inconsiderable, the links lead to constrain equations of the DOFs of the element in Fig. 6a:

$$
d_{1}=d_{2}-d_{4} \cdot h \text { and } d_{5}=d_{6}-d_{8} \cdot h
$$

Thanks to these constrain equation, the 6 DOF element in Fig.6b is obtained by eliminating the DOF's 1 and 5 in the 8DOF element in Fig. 6a, and have the stiffness matrix and the force nodal vector given by:

$$
\mathbf{K}_{\mathbf{e}(6 \mathbf{x} 6)}=\left(\mathbf{T}_{(8 \times 6)}\right)^{T} \cdot \mathbf{K}_{\mathbf{e}(8 \times 8)} \cdot \mathbf{T}_{(8 \times 6)} \text { and } \mathbf{P}_{(6 \times 1)}=\left(\mathbf{T}_{(8 \times 6)}\right)^{T} \cdot \mathbf{P}_{(8 \times 1)}
$$

where $\mathbf{T}_{(8 \times 6)}$ is the transformation matrix representing the relationship between the 8 DOFs of the element in Fig. 6a and the 6 DOFs of the element in Fig.6b:

$$
T_{(8 \times 6)}=\left[\begin{array}{llllll}
1 & 0 & -h & 0 & 0 & 0 \\
1 & 0 & 0 & 0 & 0 & 0 \\
0 & 1 & 0 & 0 & 0 & 0 \\
0 & 0 & 1 & 0 & 0 & 0 \\
0 & 0 & 0 & 1 & 0 & -h \\
0 & 0 & 0 & 1 & 0 & 0 \\
0 & 0 & 0 & 0 & 1 & 0 \\
0 & 0 & 0 & 0 & 0 & 1
\end{array}\right]
$$

Now, the 6DOF super element for modelling composite beam with PI, material nonlinearity and semi-rigid composite joints has been formulated. The transforming the 8DOF element in Fig. 6a into the 6DOF element in Fig. 6b also make possible the assembling the DOFs of the beam element's nodes to those of the column's nodes which only have 3 DOFs. 


\section{NONLINEAR ANALYSIS OF COMPOSITE FRAMES}

An important aim of the nonlinear analysis is to trace the structural equilibrium path until failure is reached. Herein, the load control method and displacement control methods are implemented for this aim. In the load control method (Fig. 7a), the displacement nodal vector corresponding with a fixed load level is solved through an iterative procedure. This method is not suitable for describing equilibrium paths with weak load

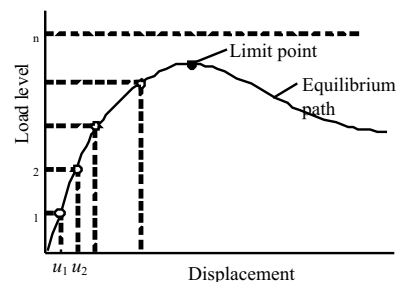

(a) Load control

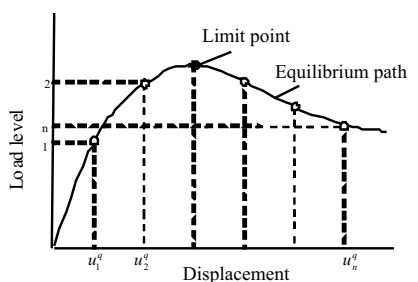

(b) Displacement control

Fig. 7. Methods for tracing the equilibrium path

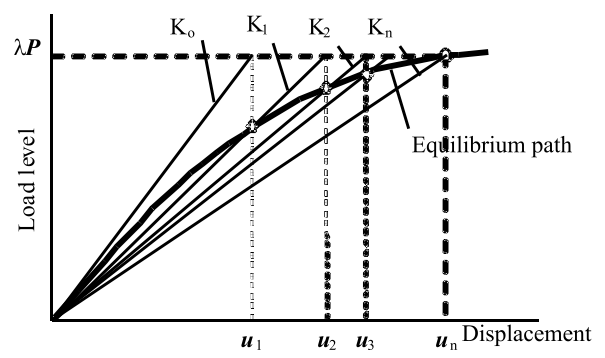

Fig. 8. The direct method

level variations and cannot trace softening equilibrium paths. In the displacement control method (Fig. 7b), a chosen component of the displacement nodal vector is fixed, and the load level and the other displacement components is solved through iterative procedure to correspond with the fixed displacement component. This method can trace equilibrium paths with weak load level variations and softening equilibrium paths as well. The iterative procedure for solving nonlinear equilibrium equation is the "direct method" (Fig. 8).

\section{NUMERICAL EXAMPLES}

To demonstrate the robustness and validity of the proposed method, a computer program, called COMFAD, is developed and employed for nonlinear analysis of a number of composite structures. The results by the proposed method are compared with experimental as well as numerical results by other authors, and are discussed for influences of PI, semirigid joints and material nonlinearity on behaviour of composite beams and composite frames. 


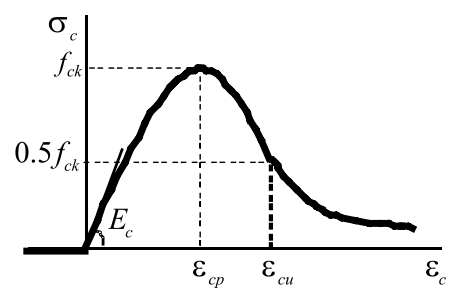

(a) Concrete

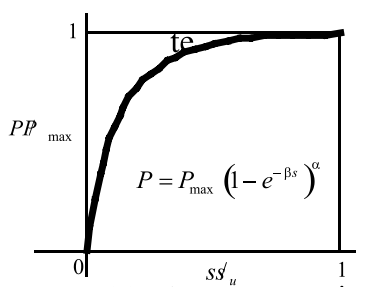

(c) Shear connection

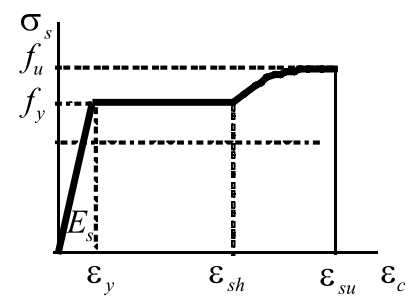

(b) Steel

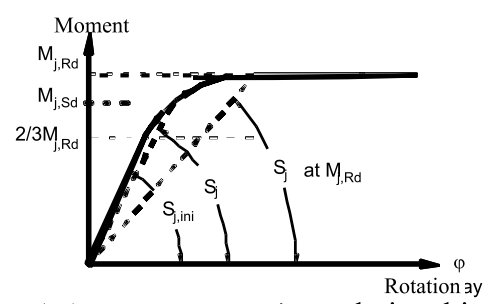

(d) Moment-rotation relationship of bare steel joint

Fig. 9. Nonlinear constitutive laws

Table 1. Geometrical properties of the test beam

\begin{tabular}{|l|l|c|}
\hline \multicolumn{2}{|l|}{ Span length $(\mathrm{mm})$} & 4500 \\
\hline Concrete slab & Thickness $(\mathrm{mm})$ & 100 \\
\cline { 2 - 3 } & Width $(\mathrm{mm})$ & 800 \\
\hline Steel beam & Section $(\mathrm{mm})$ & HEA 200 \\
\hline \multirow{2}{*}{ Reinforcement } & Top $\left(\mathrm{mm}^{2}\right)$ & 804 \\
\cline { 2 - 3 } & Bottom $\left(\mathrm{mm}^{2}\right)$ & 767 \\
\hline \multirow{3}{*}{ Shear stud } & Kind & $19 \times 75$ \\
\cline { 2 - 3 } & Spacing $(\mathrm{mm})$ & 350 \\
\cline { 2 - 3 } & Number & 84 \\
\hline
\end{tabular}

The constitutive laws adopted to describe nonlinear behaviours of materials are presented as follows. Elastic-perfect plastic-hardening constitutive law cited by [1] is used for steel and rebars (Fig. 9a). The nonlinear law suggested by CEB-FIP Model Code 1990 [5] is adopted for concrete under compression while null strength is used under tension, (Fig. 9b). The Ollgaard constitutive law cited [1] is employed for the shear connection (Fig. 9c). The rotational stiffness of the spring for modelling the bare steel joint is characterized by moment-rotation curve suggested by Eurocode 3 [6] (Fig. 9d).

\subsection{Example 1: Two-span continuous composite beam}

The composite beam CTB4, tested by Ansourian [7], was simulated by the method in this study (Fig. 10). The geometrical and material properties are reported in Table 1 and Table 2.

Fig. 11 shows the load versus midspan deflection plots by proposed method, general method by Ranzi [8] and experimental data by Ansourian. It can be seen that there are 
Table 2. Material properties of the test beam

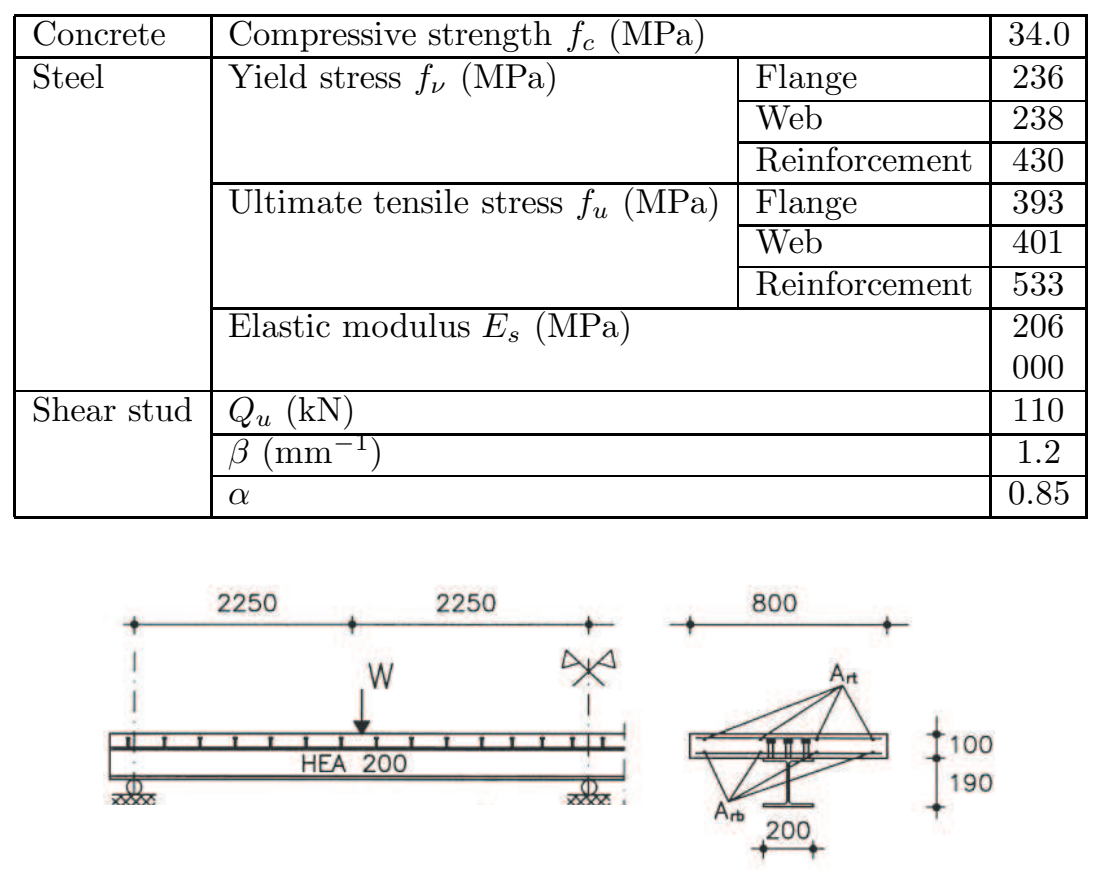

Fig. 10. The two-span continuous beam

good agreements between the results of proposed method and Ansourian's experiment in case of material nonlinearity and between the results of proposed method and Ranzi's method in case of linear material assumption. It also shows that there is obvious difference between two cases of material linearity and nonlinearity when the load $\mathrm{W}$ is above 200 $\mathrm{kN}$.

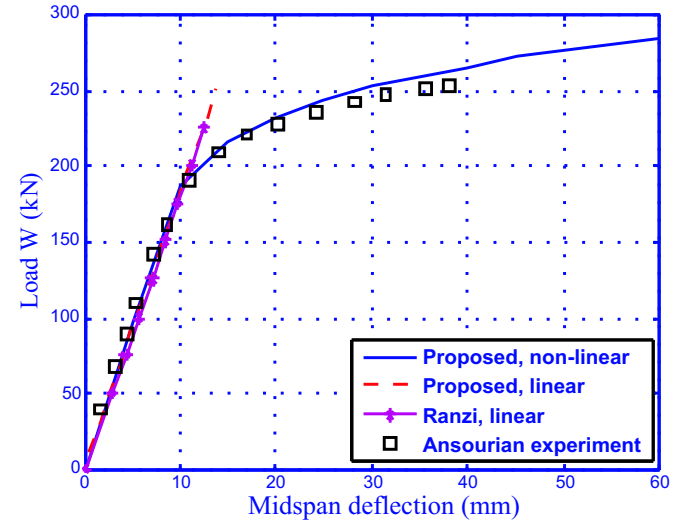

Fig. 11. Comparision between numerical results and Ansourian's experimental results

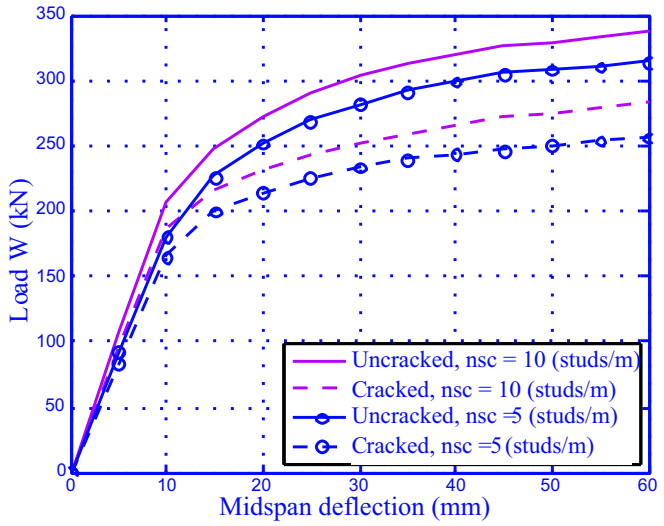

Fig. 12. Midspan deflection with cracked and uncracked concrete 
Fig. 12 shows the load versus midspan deflection plot with the assumption of cracked and uncracked concrete sections and the different degree of shear interaction. It can be seen in the figure that the crack and uncrack assumption and the shear interaction has significant influences on the behaviour of beam deflection as well as the ultimate load.

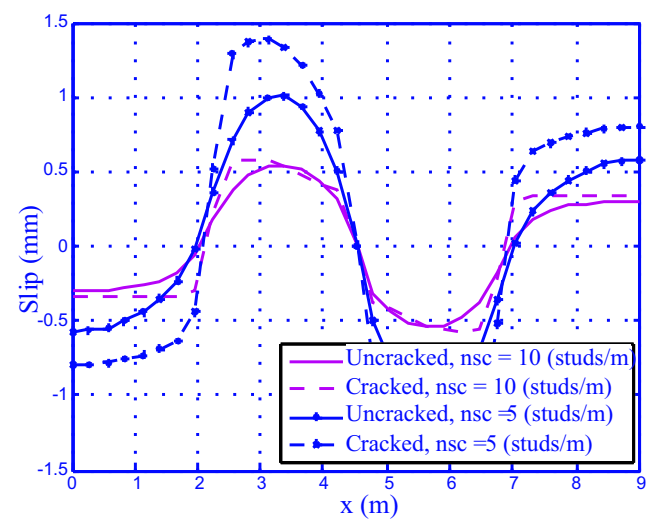

Fig. 13. Slip with cracked and uncracked concrete

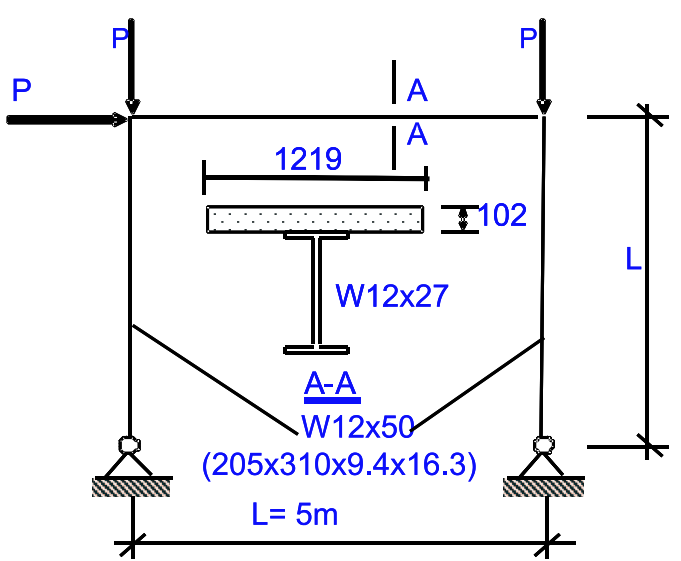

Fig. 14. Portal composite frame

Fig. 13 shows the variation of longitudinal slip along member length. The slip is also considerably affected by the cracked and uncracked assumption as well as the shear interaction. It can also be seen that the higher the degree of interaction is, the less sensitive to the consideration for craking the slip is.

\subsection{Example 2: Portal composite frame}

Fig. 14 shows the portal composite frame that was analyzed by Liew and Chen (2001) [9]. That consists of a composite beam rigidly connected to two steel columns. The geometrical of the members are shown in Fig. 14. The strength of concrete $f_{c}=16 \mathrm{MPa}$, the yield strength of steel $f_{y}=252.4 \mathrm{MPa}$, and the elastic modulus of steel $E=2 \times 10^{5}$ $\mathrm{MPa}$. The degree of shear connection is $\mathrm{N} / \mathrm{Nf}=0.9$ where $\mathrm{N}_{f}$ is the stud connections designed to obtain full interaction according to EC4.

The load versus lateral displacement curves in Fig. 15 indicates that good agreement between the results by the proposed formulation in this study and those by Liew and Chen. It can be seen that the pure steel frame collapses at $P=60.2 \mathrm{kN}$ while the composite frame at $P=82.7 \mathrm{kN}$. The limit load of the frame, thanks to the composite action, is increased by $37 \%$. However, this composite action is effective to increase the limit load when slab-to-column links are considered. If these links are not considered, the limit loads of the pure steel frame and of the composite frame are nearly the same as shown in Fig. 15.

The distributed load on the composite beam versus the midspan deflection with different degree of interaction is plotted in Fig. 16. The results indicate that shear interaction has significant influence on the deflection of the composite beam subject to distributed load as well as on the limit load. 


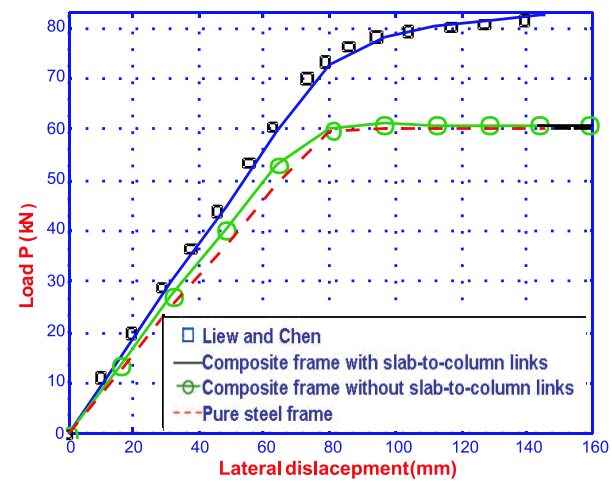

Fig. 15. Load - Displacement curves

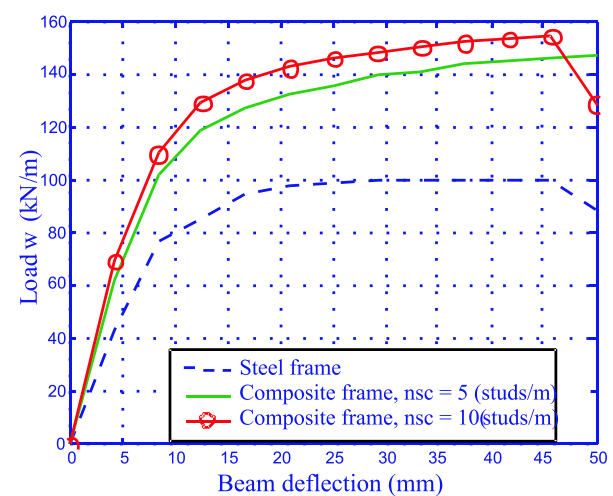

Fig. 16. Mid-span deflection of composite beam

\subsection{Example 3: Six-storey composite frame}

Analyzed herein is a six-storey composite frame with geometrical properties shown in Fig. 17, which has been by a number of researchers as benchmark examples $[10,11]$. The strength of concrete $f_{c}=25 \mathrm{MPa}$, the yield strength of steel $f_{y}=235 \mathrm{MPa}$, and the

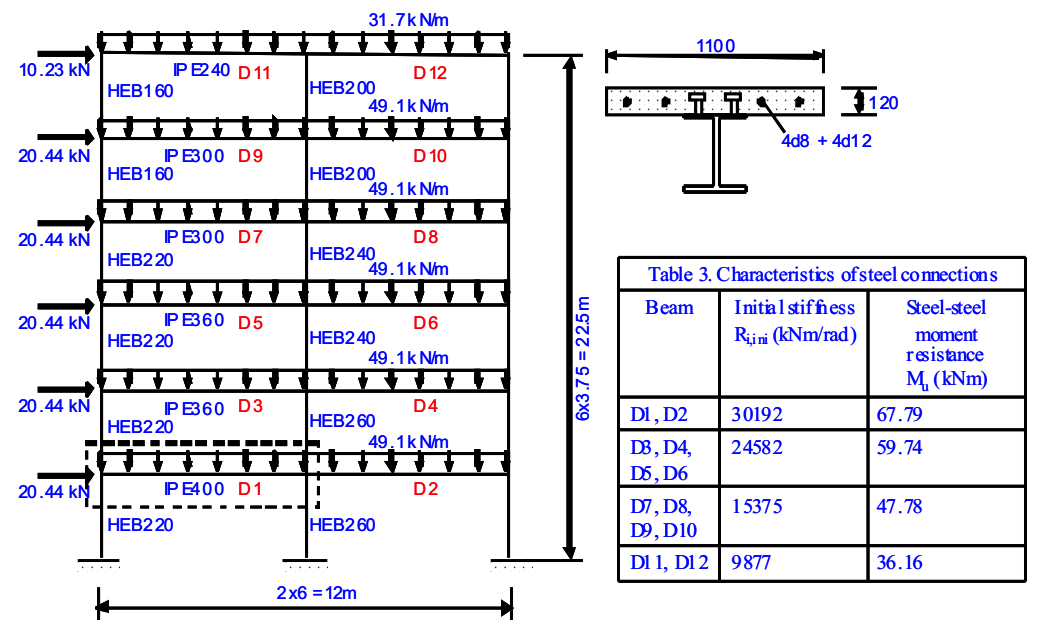

Fig. 17. Six-storey composite frame

elastic modulus of steel $E=2 \times 10^{5} \mathrm{MPa}$. The shear connections have: $\mathrm{d}_{s c}=12.7 \mathrm{~mm}, \mathrm{Q}_{u}=$ $66 \mathrm{kN} ; \beta=0.8 \mathrm{~mm}-1, \alpha=0.4$. The initial stiffness and the ultimate of bare steel connection are calculated by COMFAD according to EC3 and are shown in Table 3.

Fig. 18 shows the curves of load level versus lateral displacement at the top of frame with different degree of shear interaction between steel beam and concrete slap. The case of the steel frame with no concrete slab is also included. It can be seen that the composite action of composite beam play an important role in the stiffness of the frame and in the ultimate load as well. In case of semi-rigid frame, the figure shows that the two curves from steel frame and no-interaction frame nearly coincide. The results also show that the 
displacement is less sensitive to the degree of shear interaction in rigid frame than in semi-rigid frame.

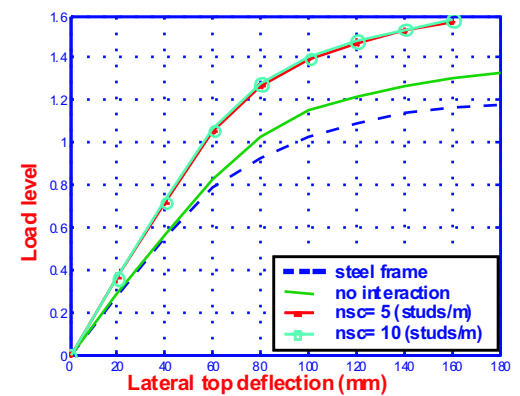

a) Rigid frame

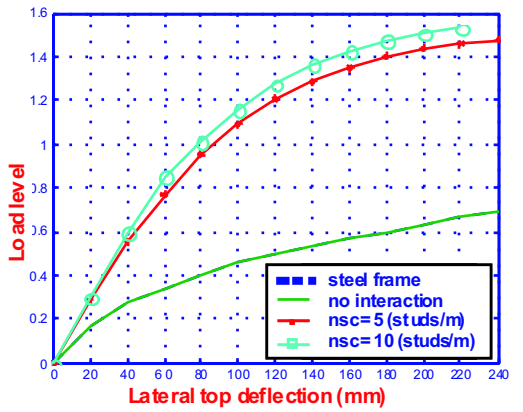

b) Semi-rigid frame

Fig. 18. Top lateral displacement vs load level

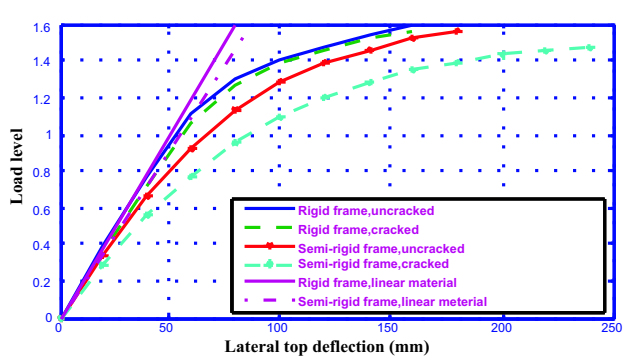

Fig. 19. Influences of cracked and uncracked sections on lateral displacement

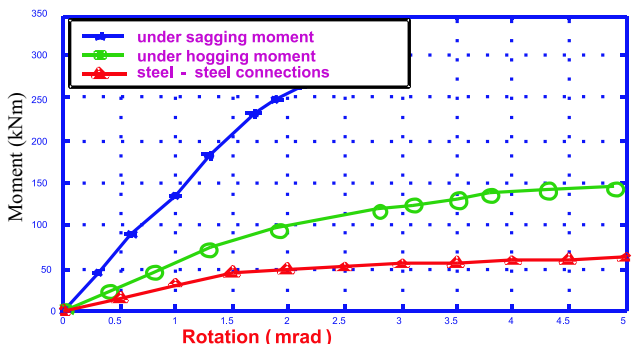

Fig. 20. Connection stiffness under hogging and sagging moment

Fig. 19 shows the load level versus later top deflection plot in cases of rigid and semi-rigid connections with the assumptions of material linearity and nonlinearity with cracked and uncracked concrete sections. It can be seen in the figure that the crack and uncrack assumptions plots obviously different results of lateral deflection and ultimate load as well. The results also show such differences are more distinct in rigid frame than in semi-rigid frame.

Fig. 20 shows the behaviour of the composite connections under sagging and hogging moment. It can be seen that the stiffness of the composite joint is visibly larger than the stiffness of bare steel connection's contribution. The results also indicate the considerably different behaviour of the composite joints under sagging and hogging moments.

\section{CONCLUSIONS}

This study presentes a displacement-based finite element formulation for nonlinear analysis of steel-concrete composite planar frames. A 6DOF super element for modelling the composite beam is proposed. This element is able to allow for partial interaction, material nonlinearity and semi-rigid connections. The nonlinear behaviour of materials of this element derives entirely from the constitutive laws. This element also has the ability to consider different behaviour of semi-rigid composite joints under sagging and hogging 
moments. An algorithm for solving nonlinear analysis of composite structures with both load control and displacement control is also proposed.

From the numerical examples, the validation of the formulation is demonstrated by good agreement between the results from proposed formulation with experimental data or results from other studies. The partial interaction, material nonlinearity and semirigid connections have significant influences on behaviour of composite beams as well as composite frames, which are more sensitive to these factors in semi-rigid frame than in rigid frame.

\section{REFERENCES}

[1] Dall'Asta A and Zona A., Non-linear analysis of composite beams by a displacement approach, Comput Struct, 80(27-30) (2002), 2217-2228.

[2] Dall'Asta A and Zona A., Three-field mixed formulation for the non-linear analysis of composite beams with weak shear connection, Finite Elem Anal Des, 40(4) (2004), 425-448.

[3] Batoz J.L and Dhatt G., Incremental displacement algorithms for non-linear problems, Int. J. Numer. Meth. Engng, 14(8) 1979, 1262-1267.

[4] Zienkiewicz O.C., Taylor R.L., The Finite Element Method: The Basis, 1 (2000), ButterworthHeinemann, 5th Edition.

[5] Structural Concrete: Textbook on Behaviour, Design and Performance : Updated Knowledge of the CEB/FIP Model Code 1990 (1999). Fédération internationale du béton, Fédération internationale du béton.

[6] EN 1993 - Eurocode 3: Design of steel structures, European Committee for Standardization (CEN) (2004).

[7] Ansourian P., Experiments on continuous composite beams, Proc Inst Civil Eng, Part 2, 71 (1981), 25-51.

[8] Ranzi G., Gara F., Ansourian P., General method of analysis for composite beams with longitudinal and transverse partial interaction, Computers and Structures, 84 (2006), 2373-2384.

[9] Liew J. Y. R., Chen H., Shanmugam N. E. and Chen W. F., Inelastic Analysis of Steel Frames with Composite Beams, J. Struct. Eng., 127 (2) (2001), 194-202.

[10] Fang L.X., Chan S.L. and Wong Y.L., Strength analysis of semi-rigid steel-concrete composite frames, Journal of Constructional Steel Research, 52 (1999), 269-291.

[11] Fang L.X, Chan S.L and Wong Y.L., Numerical analysis of composite frames with partial shear-stud interaction by one element per member, Engineering Structures, 22 (2000), 12851300 .

Received January 20, 2010 